\title{
Correction: Conditional replication of oncolytic viruses based on detection of oncogenic mRNA
}

\section{Renteln}

Published online: 7 January 2021

(c) The Author(s), under exclusive licence to Springer Nature Limited 2021

Correction to: Gene Ther

https://doi.org/10.1038/gt.2017.99

Since publication of the article, the authors noticed there was an error about the amount of packaging space in HSV-1/2. The authors have provided the following explanation:

With regard to the multi-sample sequencing I mentioned in the abstract, technically one can identify truncal mutations by multi-region sequencing of the primary tumor alone. However, it would be best to sequence cells from multiple regions of all the metastases as well as the primary tumor before selecting one or more target transcripts. This is because one or more cancer cells may have lost the targeted mutation(s) and metastasized from the primary tumor or another metastasis. Alternatively, a large portion of one or more metastases could be comprised of cancer cells that have lost the targeted mutation(s) due to an event or events that occurred soon after metastasis.

I should have said that herpes simplex virus type 1 (and possibly type 2) may be an ideal vector for treatment because one may be able to add a fair amount of extra DNA to its genome and/or delete a relatively large number of viral genes without affecting its replication, which could potentially allow one to target multiple relevant mutations simultaneously and equip the virus with many of the conceivable therapeutic genetic elements. 